\title{
On-Site Architectural Drawing with Hand-held Mobile Instructions
}

\author{
Nan-Ching Tai
}

\begin{abstract}
The advances in computer-aided design tools have enabled design visualization and realization to become more efficient and effective. However, these fast-growing digital technologies are also gradually reducing the presence of hand drawings in architectural education. This leads to a reduction in the ability to be inspired from the direct observation of the architectural environment through on-site freehand sketching. This study aims to implement digital technology as a teaching aid to retrieve these lost abilities. Analytical drawing is a method that encourages thinking before drawing, laying out the invisible underlying structure, and finalizing it with a visible appearance. This method remains an effective way of three-dimensional visual thinking. Accordingly, this study presents an interactive smartphone application that brings computer-assisted instructions into mobile learning. Promising responses from students revealed that using digital technology as a teaching aid can help to retrieve the lost abilities of visual thinking through on-site sketching.
\end{abstract}

Index Terms-Mobile learning, computer-assisted instruction, mobile application, on-site sketching.

\section{INTRODUCTION}

Architectural design has been mediated through drawings using standardized rules that everyone involved in the design and construction process can understand. As a result, teaching architectural drawing has become essential to architectural education [1], [2]. The fundamental principles of architectural drawing involve mapping the three-dimensional (3D) geometrical relationships of an object or scene onto a two-dimensional (2D) surface [3]-[5]. Over time these principles have basically remained the same, but the methods have evolved in line with the technological advancements. The rapid advancements made in digital technology in recent decades have allowed direct geometrical construction in three dimensions in a virtual environment as well as the extension of design considerations through various computer-aided design (CAD) software [6]. Although these CAD capabilities greatly advance the architectural design in many aspects, it does, unfortunately, lead to a gradual phasing out of the architectural drawing in the form of a conventional hand drawing and drafting. This phenomenon ultimately influences the future generation of designers to emphasize more on the mouse than on the pen while they are learning.

Manuscript received May 1, 2021; revised August 8, 2021. This work was supported in part by the Ministry of Education in Taiwan under the Teaching Practice Research Program (PHA1080220).

Nan-Ching Tai is with the National Taipei University of Technology, Taipei, Taiwan (e-mail: nctai@mail.ntut.edu.tw).
Analytical drawing is a method that encourages the freehand drawing of a 3D subject. Analytical drawing, first developed during Renaissance [3], involves drawing both the inner structure and the exterior appearance of a subject. As a result, analytical drawing resembles 3D thinking to a greater degree than drawing. As both the freehand analytical drawing and 3D computer modeling are based on the same architectural drawing principles, their underlying 3D thinking process can help each other. Fig. 1 illustrates this relationship. The understanding of the stepwise developments of the 3D spatial configuration can, in turn, be used to build a 3D model.
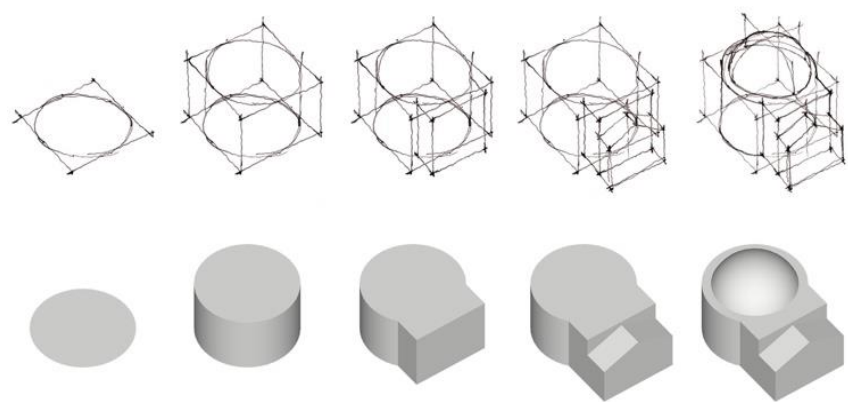

Fig. 1. Interrelationship of the 3D thinking process between an analytical drawing and a 3D modeling of the Pantheon.

The interrelationship of the 3D thinking process between the analytical drawing and the 3D modeling of the same subject illustrates the importance of freehand drawing. It has to be pointed out that what has been neglected by computational architectural graphics may not just be the "old school" freehand drawing, but also the abilities of 3D thinking and visualization. In light of this, a course named "Analytical Sketching" has been dedicated to promoting these abandoned artistic abilities in architectural education. In this course, the concepts and principles of the analytical drawing process were implemented in on-site architectural sketching, thus promoting it as a method to study the encountered architectural environment through 3D thinking and visualization with the flow of the hand-drawn lines.

Nowadays, smartphones have become widely available to students, and digital technology has advanced so that smartphones possess the processing power of a computer with better mobility and interactivity. This study experimented with related digital technologies for computer graphics with a different approach. Instead of replacing conventional drawing, computer technologies were utilized to assist the teaching and learning of freehand on-site architectural sketching. A mobile application was developed to address the dilemma observed in the field of teaching and made available to students. Methods of conventional and computer-assisted teaching were then compared. Reflections 
are reported to conclude this study to inspire future possible improvements.

\section{TEACHING FRAMEWORK FOR ANALYTICAL SKETCHING}

Analytical sketching utilizes an analytical drawing process for freehand on-site sketching. As analytical on-site sketching involves one person's seeing, thinking, and drawing, the teaching thus employed respective methods to address different aspects of required engagements. The course is structured to include three major teaching activities: slide presentations in the classroom to deliver the base knowledge and underlying principles, on-site demonstrations to exhibits the sketching process of various topics, and one-on-one on-site feedback to track students' learning. Fig. 2 illustrates this typical teaching framework of analytical on-site sketching using one topic of perspective sketching as an example.

The slide presentations can overlay the real scene with animated graphics to explain various concepts such as perspective elements, pictorial depth cues, or geometrical disassembling and reassembling. In Fig. 2(a), an example of developing imaginary planes to help establish a base reference to further disassemble a complex scene into a collection of simple geometries is shown using animation. After establishing the fundamental concept of each topic, on-site sketching is used to examine the acquired knowledge with hands-on practice. With the conceptual understanding gained from the slide presentations, sketching on site began with the instructor's demonstration [Fig. 2(b)]. This method often demonstrates the analytical process of sketching the subject on site, allowing for the instructor to reinforce the conceptual theories through direct reference to the architectural building before everyone's eyes. Furthermore, it demonstrates the analytical drawing process both in $3 \mathrm{D}$ visualization and in a drawn, 2D version. After the underlying concepts and their drawing implementations are brought together through the demonstration, the students proceed to sketch on site. This is done while the instructor provides feedback with reference to what the students see and draw as an effort to carefully track the development of individual students with regard to the understanding of that particular architectural subject with the emphasized topic [Fig. 2(c)].

Various topics can be taught using the same teaching framework; however, several dilemmas have surfaced in teaching in the past few years, namely: 1) the in-class or on-site weekly meeting might often reduce the effectiveness of the slide presentation, as it might be difficult for students to remember what was taught or presented in the classroom when the class meets again at the site after a longish break; 2) without visual aids on site, conveying imagined geometrical analysis verbally is hard; and 3) one-on-one feedback might make students wait too long to get the feedback because of the number of enrolled students. These issues essentially arise due to the unique characteristics of teaching both on site where the preferred architecture is located, and off-location in the classroom where computers and projectors are available. Accordingly, solutions for these problems are sought through the integration of computer-assisted learning with mobile learning to assist learning across different locations and times.
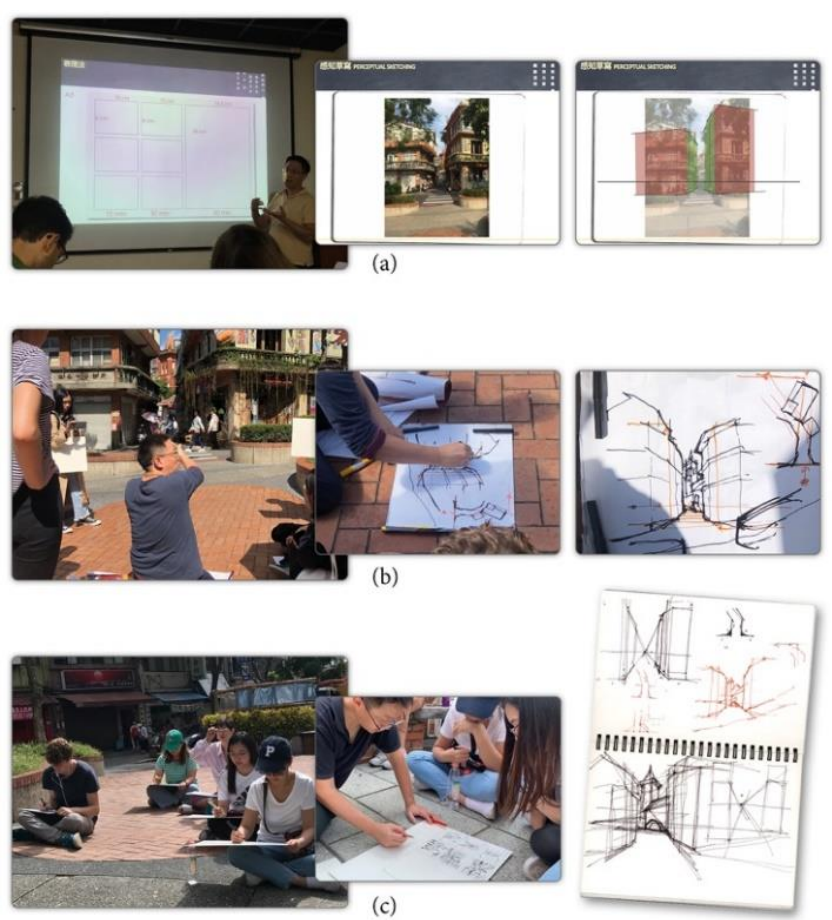

Fig. 2. Teaching framework.

\section{MOBILE LEARNING AND COMPUTER-ASSISTED INSTRUCTION}

Mobile learning is not a new idea; it has been carried out in various forms such as reading tangible memory vocabulary cards or listening to intangible audio instructions. As long as one can continually learn while on the move, the employed method can be considered mobile learning [7], [8]. Computer-assisted instruction, in contrast, refers to the use of computer technologies with programmed interactive materials to help users self-learn [9], [10].

Various innovative mobile on-site sketching applications have been made available on a digital hand-held device such as Sweep-Canvas and Mobi3Dsketch, allowing users to sketch on a 2D screen and create $3 \mathrm{D}$ objects augmented to the real scene [11], [12]. However, the intent of analytical sketching is not only to teach the method but also to develop a freehand drawing technique among students. The course, therefore, encourages students to draw with a fountain pen for it can generate different line weights, allowing one to sketch an object as it appears to one's eye as well as how it exists in reality. As illustrated in Fig. 3. Sketch backward of the fountain to use thin and light lines to construct the entire geometrical configuration, as shown in Fig. 3(a); follow it by medium line weight for the visible lines that our eye can see [Fig. 3(b)], and finally overlay the heavy line weight to enhance the three-dimensionality [Fig. 3(c)]. To this end, the mobile app developed for this course is not intended to replace but to supplement the art of sketching.

A prior study based on action research has been conducted to investigate the creation of computer-assisted instructions for analytical sketching suitable for smartphones [13], [14]. Experimental prototypes of mobile applications were implemented during actual teaching, using the repetitive 
processes of "plan," "action," "observation," and "reflection" to identify student preferences. The results suggested that a step-by-step illustration of the analytical sketching process can be highly beneficial for learning on-site sketching. To helpfully navigate the process, the user can click to advance to the next stage with a text explanation and swipe to show the sequence as animation with preferred speed [15], [16].
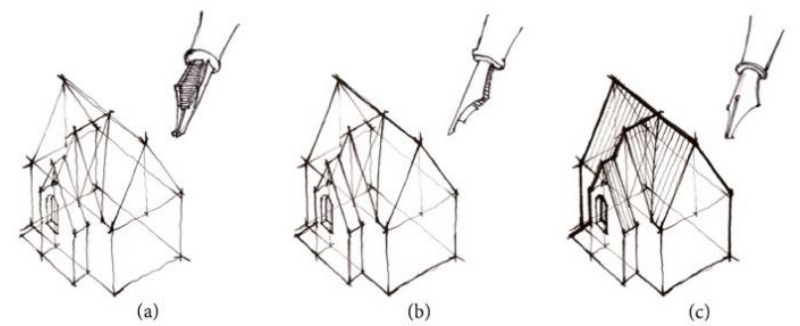

Fig. 3. Line weight techniques of analytical sketching.

In this study, a mobile application (App) named Architectural Sketching was developed. Notably, there are three features, with each responding to the three major teaching activities. The animated explanations of related topics of analytical sketches were created and placed in the menu item of "Analytical Drawing." This section provides knowledge delivered in the classroom slide presentation. In the menu item of "Sketching Video," a list of buildings can link to the on-site demonstration of sketching, allowing users to review the instructor's live demonstration anytime and anywhere. The stepwise illustrations of perspective sketching provide the key developments of analytical sketch, serving as a replica of the instructor's one-on-one feedback that is often directly drawn on the student's sketchbook.

Fig. 4 illustrates the operational flow of the App. Click the buttons on the bottom to select a category. For "Analytical Drawing," various topics can be selected from the list. Fig. 4 illustrates the topic of perspective types. As shown, translucent graphs are overlaid with photos to explain the basic spatial configuration of linear perspective. By clicking the dots on the bottom of the screen, students can refresh the learned information explained with a similar graphical representation in the classroom presentation. This feature bridges the conveyed information that might fade away in memory from the classroom to the site. More importantly, it can also serve as a library for students to review the related fundamental concepts of analytical drawing throughout the class from time to time.

"On-site analytical sketching" includes a list of images of buildings along with their simple descriptions that are provided for quick reference. A click can view the analytical process of perspective sketching; accordingly, by clicking a dot at the bottom, it advances to the next stage along with instructions. Swiping the slider can play the sequential image in animation at a preferred speed. This dual-user interaction allows for a careful stepwise study as well as a quick grasp of the sketching procedure.

In the "Sketching Video", a list of buildings along with a simple description is also provided. Videos of sketching a particular building were recorded in advance, edited, and uploaded to the online platform YouTube (https://www.youtube.com). Clicking the image on the building will open the link to the video from the YouTube channel. The video can also be played on a tilt screen with a full-size screen. This feature allows students to review on-site demonstrations on their own anytime they want.

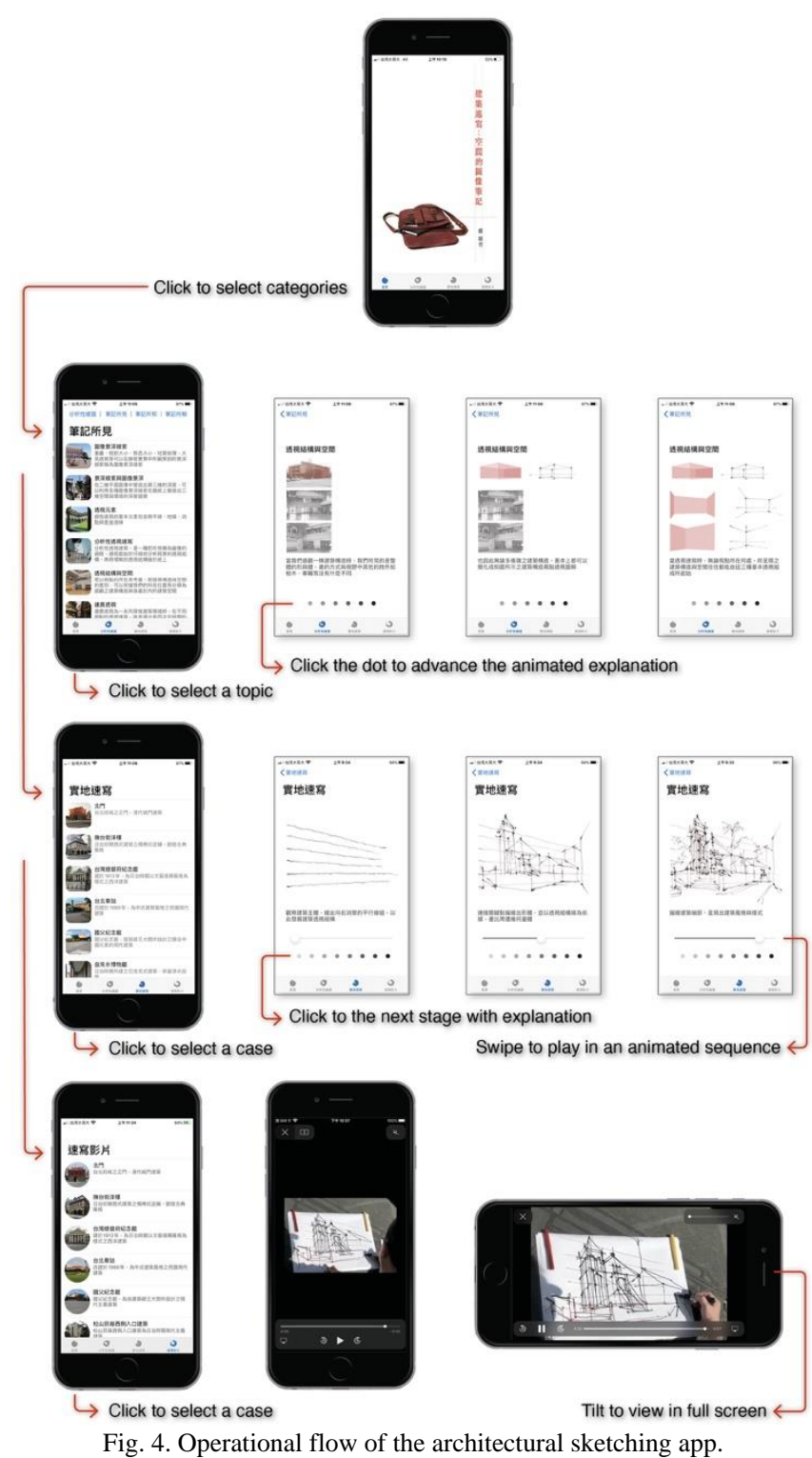

\section{REFLECTION FROM THE TEACHING IMPLEMENTATION}

The mobile Architectural Sketching App was made available to two groups of students who were learning analytical sketching. One group consisted of graduate students enrolled in a sketching course and the other group were undergraduate students enrolled in a design drawing course. The content related to analytical sketching was taught in the same manner for the two classes. Questionnaires were collected to evaluate the effectiveness of this mobile interactive learning application. Subsequently, 20 and 15 responses were collected from the graduate students and undergraduate students, respectively. The following were the two main aspects evaluated by the questionnaire survey: one for the whole class and one for the features of the mobile application. For the class as a whole, we wanted to know which among the three teaching activities, classroom slide presentation, on-site demonstration, and one-on-one feedback, would help students the most. For the mobile 
application, we wanted to know which among the three features of interactive concept explanation, stepwise illustrative tutorial of the sketching process, and the demonstration video clip, would be the most useful.

Two evaluation methods of rank-ordering and forced-choice were employed. For rank-ordering, students were asked to rate a particular teaching method/assistance with a five-point scale, ranging from one to five, representing "Strongly Disagree," "Disagree," "Neutral," "Agree," and "Strongly Agree," respectively. The higher the average of the rated score, the greater the help. The items that were presented in the questionnaires for this method of preference rating are listed below:

For the course as a whole:

1) The slide presentation in the classroom helps me a lot.

2) The instructor's on-site demonstration helps me a lot.

3) The instructor's on-site one-on-one feedback on my sketches helps me a lot.

For mobile learning:

1) The interactive concept explanation helps me a lot.

2) The stepwise illustrative tutorial helps me a lot.

3) The demo video helps me a lot.

Perceptual preference of a list of items can be more effectively differentiated using the forced-choice method. Paired stimulus preference assessment has been validated that can be more sensitive to derive participant's perceptual preference [17]. In this type of evaluation, each item is paired with another, participants thus need to compare the two and were forced to pick a preferred one. The total number of the preferred picks would establish a preference order of total items. The questions presented in the questionnaires for this method of preference order are listed below:

1) Among the three teaching activities, please check one from each pair that you think helps you the most.

\begin{tabular}{|l|l|}
\hline Classroom Presentation & On-site Demonstration \\
\hline & \multicolumn{2}{|l|}{} \\
\hline On-site Demonstration & One-on-one Feedbacks \\
\hline \multicolumn{2}{|c|}{} \\
\hline One-on-one Feedbacks & Classroom Presentation \\
\hline & \\
\hline
\end{tabular}

2) Among the three supplementary learning materials, please select one from each pair that you think helped you the most in learning analytical sketching.

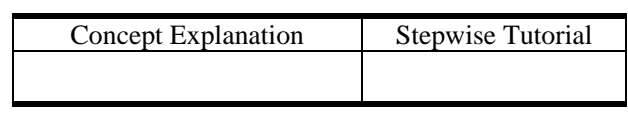

\begin{tabular}{|l|c|}
\hline Stepwise Tutorial & Demo Video \\
\hline & \\
\hline \multicolumn{2}{|l}{} \\
\hline Demo Video & Concept Explanation \\
\hline & \\
\hline
\end{tabular}

Table I illustrates the rating results along with the preference order of total preferred picks. The two results are in agreement. For the total of 35 students, the teaching method of one-on-one feedback is considered the most helpful, followed closely by the on-site demonstration, whereas the slide presentation in the classroom finished last.

TABLE I: PREFERENCE RATING AND PREFERENCE ORDER FOR TEACHING METHODS

\begin{tabular}{lcc}
\hline & $\begin{array}{l}\text { METHODS } \\
\text { (Average) }\end{array}$ & $\begin{array}{l}\text { Preference order } \\
\text { (Preferred picks) }\end{array}$ \\
\hline \hline $\begin{array}{l}\text { One-on-one feedback } \\
\text { On-site demonstration }\end{array}$ & 5.00 & 56 \\
$\begin{array}{l}\text { Slide presentation in the } \\
\text { classroom }\end{array}$ & 4.90 & 41 \\
\hline \hline
\end{tabular}

Table II shows the preference rating and preference order of total preferred picks for each feature of the mobile app, the interactive "concept explanation," "stepwise tutorial" of the sketching process, and the "demo video"; they are at 4.45 , 4.50 , and 3.85 , respectively. It is also aligned with the preference order. However, although the preference ratings for concept explanation and stepwise tutorial are very close, the difference in preferred picks by the forced-choice method is more significant, thus implying that forced-choice might be a better way to reveal which method provides more help to students.

TABLE II: PREFERENCE RATING AND ORDER OF MOBILE COMPUTER-ASSISTED INSTRUCTION

\begin{tabular}{lcc}
\hline \hline & $\begin{array}{l}\text { Preference rating } \\
\text { (Average) }\end{array}$ & $\begin{array}{c}\text { Preference order } \\
\text { (Preferred picks) }\end{array}$ \\
\hline Stepwise tutorial & 4.50 & 52 \\
Concept explanation & 4.45 & 34 \\
Demo video & 3.85 & 19 \\
\hline \hline
\end{tabular}

The results of the survey reflect that the engagement levels of students are high during hands-on activities. It is evident in the perfect score of 5.00 for the rating of perceived effectiveness of the one-on-one feedback. During one-on-one feedback, students can put to test their learned knowledge with their hand sketches, revealing the individual problems that he or she can make an effort to improve based on the instructor's immediate feedback. In contrast, the classroom slide presentation received the lowest perceived effectiveness. This response can also be expected from past teaching experience. The in-classroom presentation is often used to prepare students for the upcoming field trip of on-site sketching, either in the second half of the class at a nearby site or to a distant location in the next class. As sketching on-site is often more appealing for students, sitting in the classroom might not be as fun compared with going out and sketching. However, even though the rating is the lowest among the three, it still has a high score of 4.40, indicating that students appreciate learning the background knowledge and theoretical foundation that helps the hands-on practice. The on-site demonstration also receives high satisfaction from students, falling just a little short compared with one-to-one feedback. A possible reason might be that an on-site demonstration sometimes cannot effectively convey the subject matter due to the absence of visual aids. When explaining the geometrical configuration through 
imagination, students might not completely understand what geometrical disassembling was imagined by the instructor. The discrepancy of not fully grasping the demonstration can often be detected by the instructor during one-on-one feedback. This observation is also the initial motivation to develop a mobile learning application to provide on-site visual references regarding abstract concepts.

For the three features of mobile application, the fact that the stepwise tutorial of the sketching process is preferred over the interactive concept explanation somewhat reflects the same preference of the teaching method of the on-site demonstration and one-on-one feedback over the concept of the classroom slide presentation. While explaining the concepts is essentially a simplified version of the classroom slide, the stepwise illustrative sketching process is more a visual tutorial of exactly how the on-site sketching can be carried out. It is not surprising that students who are more engaged in hands-on practice prefer the features of the mobile application designed for that purpose. What is surprising is the unexpected low preference rating (3.85) of the demo video. The demo video is essentially a more faithful recreation of the on-site demonstration than the stepwise tutorial. However, the students preferred the abstract instructional stepwise illustration rather than the video. The students did express that the video is often too long to repeatedly watch as it might require them to spend three to five minutes to review the entire process. The stepwise illustration, contrarily, breaks the visual process into several steps, showing the key developments graphically along with simple instructions, which then allows for the students to grasp the overall process quickly.

To further understand how mobile learning materials can assist on-site teaching and learning, another round of the questionnaire survey was conducted for a particular session of on-site sketching. The topic of this particular session was learning the perspective sketching of a contemporary Chinese architectural work that exhibits a unique configuration of rectangular and curvature forms (Fig. 5). This survey intended to cross-compare both the direct and indirect teaching activities implemented on-site. This included the instructor's on-site demonstration and one-on-one feedback as well as the stepwise tutorial and demo video available on the mobile application. The questionnaire simply asked the students which of the paired methods or materials he or she thought could better help them when learning perspective sketching on site. Subsequently, 15 undergraduate students participated in the survey. Table III illustrates the results. The order of preferred methods was as follows: One-on-one feedback, on-site demo, stepwise illustration, and demo video. The results demonstrate that although mobile learning materials have been proven to be helpful to students when compared with the direct interaction of teaching and learning with the instructor, the conventional teaching method remained the preferable choice.

TABLE III: PREFERENCE SCALE FOR AVAILABLE LEARNING METHOdS AND MATERIALS

\begin{tabular}{cccc}
\hline \hline $\begin{array}{c}\text { One-on-one } \\
\text { feedback }\end{array}$ & $\begin{array}{c}\text { On-site } \\
\text { demonstration }\end{array}$ & $\begin{array}{c}\text { Stepwise } \\
\text { tutorial }\end{array}$ & $\begin{array}{c}\text { Demo } \\
\text { video }\end{array}$ \\
\hline 38 & 35 & 12 & 5 \\
\hline \hline
\end{tabular}

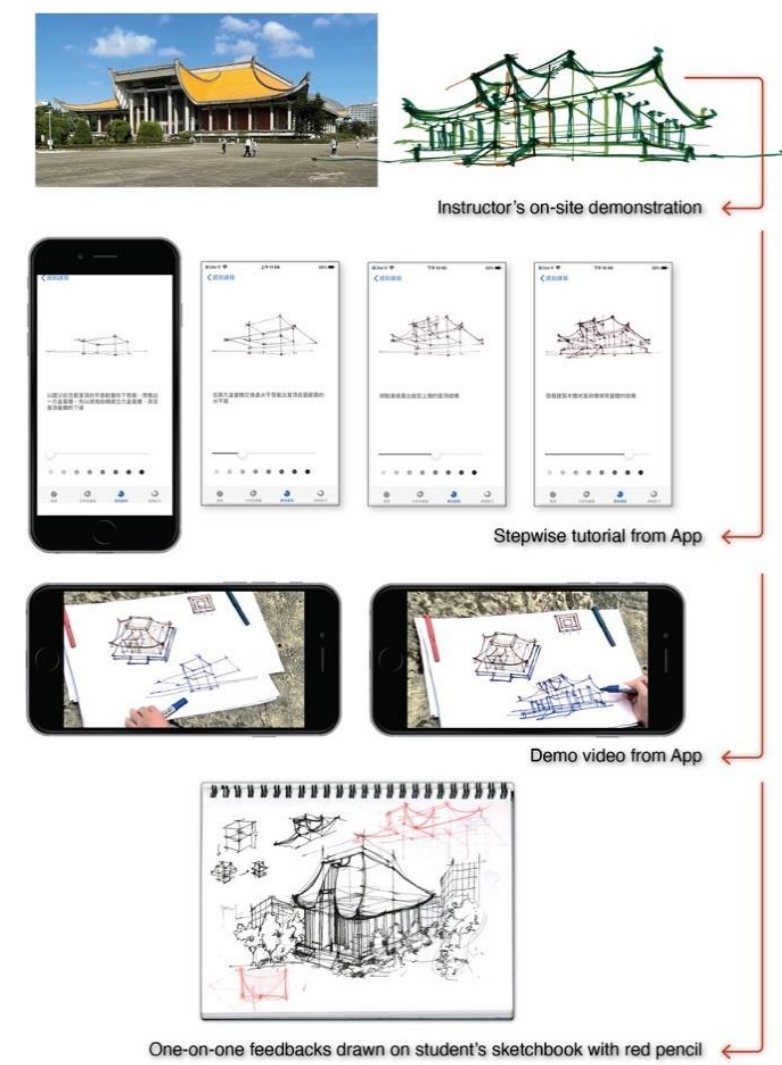

Fig. 5. Methods to assist the on-site learning of perspective sketching of Sun Yat-sen Memorial Hall.

\section{CONCLUSION}

As the nature of analytical sketching focuses more on the process of drawing than the resultant image, teaching methods that can track an individual's progress are heavily emphasized by the instructor. Teaching a particular topic of analytical sketching comprises explaining the underlying theory and principles using slide presentations, on-site demonstrations, and one-on-one feedback. Notably, the one-on-one feedback often comprises the most class time of the three, as it is the method that can truly track students' progress in terms of knowledge and skills acquired. This was also recognized by the students, as one-on-one feedback was considered the most important and most helpful method by them. The students' preference for the three major features available on the mobile application that was designed to assist in the learning of on-site sketching also reflects their preference for learning sketching with hands-on practice. Although students do recognize the utility of interactive concept explanation through mobile apps, which can help students refresh the knowledge conveyed in the classroom previously, the most frequently used and the most appreciated feature of the mobile application is the stepwise tutorial of the sketching process. By reviewing the graphical representation of the key developments of the spatial configuration of the subject, students can visualize the analytical sketching process and reinforce their understanding by scrutinizing the actual building before their eyes. The students' significant preference for the stepwise tutorial over the demonstration video further attested to the effectiveness of the integration of mobile learning with computer-aided instruction. Using the programmed content 
with intuitive user interaction, the abstracted digital information of the sketching process, in turn, can be more effectively conveyed to students as opposed to faithfully recording the entire sketching process as a video clip. To this end, we believe that computer-aided instruction mediated through mobile learning can be of significant help in teaching analytical sketching on site. However, the study also demonstrates that the mobile learning application can play a key role in anchoring class activities, but should not rely solely on it. The direct interaction between the instructor and the student on site is still irreplaceable in the context of teaching analytical sketching.

\section{CONFLICT OF INTEREST}

The authors declare no conflict of interest.

\section{REFERENCES}

[1] F. D. K. Ching, Architectural Graphics, 6 edition, Hoboken, NJ: Wiley, 2015.

[2] M. Zell, Architectural Drawing Course: Tools and Techniques for 2-D and 3-D Representation, 2 edition, New York: B.E.S. Publishing, 2018.

[3] F. Dubery and J. Willats, Drawing Systems, London: Studio Vista, 1972.

[4] J. Willats, Art and Representation: New Principles in the Analysis of Pictures, Princeton, NJ: Princeton University Press, 1997.

[5] F. D. K. Ching, Design Drawing, New York: Van Nostrand Reinhold, 1998.

[6] Y. Kalay, Architecture's New Media: Principles, Theories, and Methods of Computer-Aided Design, Cambridge, MA: MIT Press, 2004.

[7] M. Ally, Mobile Learning: Transforming the Delivery of Education and Training, Athabasca University Press, 2009.

[8] H. Crompton, "A historical overview of m-learning," Routledge Handbooks Online, 2013.

[9] P. Suppes and M. Morningstar, "Computer-assisted instruction," Science, vol. 166, no. 3903, pp. 343-350, 1969.

[10] R. M. Gagné, W. Wager, and A. Rojas, "Planning and authoring computer-assisted instruction lessons," Educational Technology, vol 21, no. 9, pp. 17-26, 1981.

[11] Y. Li, X. Luo, Y. Zheng, P. Xu, and H. Fu, "SweepCanvas: Sketch-based 3D prototyping on an RGB-D image," in Proc. the 30th Annual ACM Symposium on User Interface Software and Technology, New York, NY, USA, Oct. 2017, pp. 387-399.
[12] K. C. Kwan and H. Fu, "Mobi3DSketch: 3D sketching in mobile AR," in Proc. the 2019 CHI Conference on Human Factors in Computing Systems, New York, NY, USA: Association for Computing Machinery, 2019, pp. 1-11.

[13] D. J. Sumara, T. R. Carson, and T. Carson, Action Research as a Living Practice, New York: Peter Lang Inc., International Academic Publishers, 1997.

[14] P. Reason and H. Bradbury, Handbook of Action Research: Participative Inquiry and Practice, London, Thousand Oaks, Calif.: SAGE, 2001.

[15] N.-C. Tai, "Smartphone mobile-learning application for implementing analytical drawing process in on-site sketching," in Proc. 2019 IEEE International Conference on Consumer Electronics - Taiwan (ICCE-TW), May 2019, pp. 1-2, doi: 10.1109/ICCE-TW46550.2019.8991737.

[16] N.-C. Tai, "Self-learning at right location and right time for architectural sketching: development and implementation of learning materials of hardcopy sketchbooks and mobile applications," Journal of Scholarship of Teaching and Learning, vol. 1, no.1, pp. 129-140, 2021, doi: 10.7007/JSoTL.202103_1(1).0005.

[17] W. Fisher, C. C. Piazza, L. G. Bowman, L. P. Hagopian, J. C. Owens, and I. Slevin, "A comparison of two approaches for identifying reinforcers for persons with severe and profound disabilities," J. Appl. Behav. Anal., vol. 25, no. 2, pp. 491-498, 1992, doi: 10.1901/jaba.1992.25-491.

Copyright (C) 2022 by the authors. This is an open access article distributed under the Creative Commons Attribution License which permits unrestricted use, distribution, and reproduction in any medium, provided the original work is properly cited (CC BY 4.0).

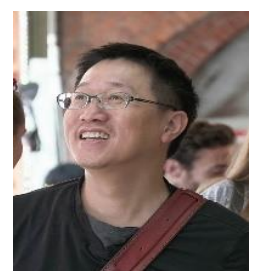

Nan-Ching Tai received his master degree in architecture and Ph.D. in the built environment from the University of Washington. He is currently a faculty member at Department of Interaction Design of National Taipei University of Technology. His teaching and research interests are in the area of visual language. He believes that sketching freehand analytically is a means by which to think and create in the field of design and thus can be considered as a native visual language. To communicate and realize a design idea, he believes computer graphics are an advanced common visual language. He notes that the development of high-dynamic-range-imaging-related technologies continue to advance visual realism. To this end, his research interests focus on developing a computational framework for creating a pictorial environment that can reflect perceptual reality and using this alternative environment to investigate the various issues related to space perception in the field of design. 